22.2

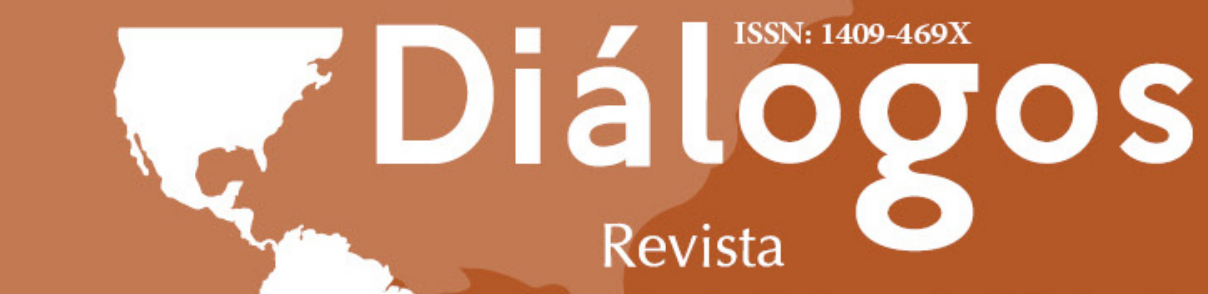

Electrónica de Historia

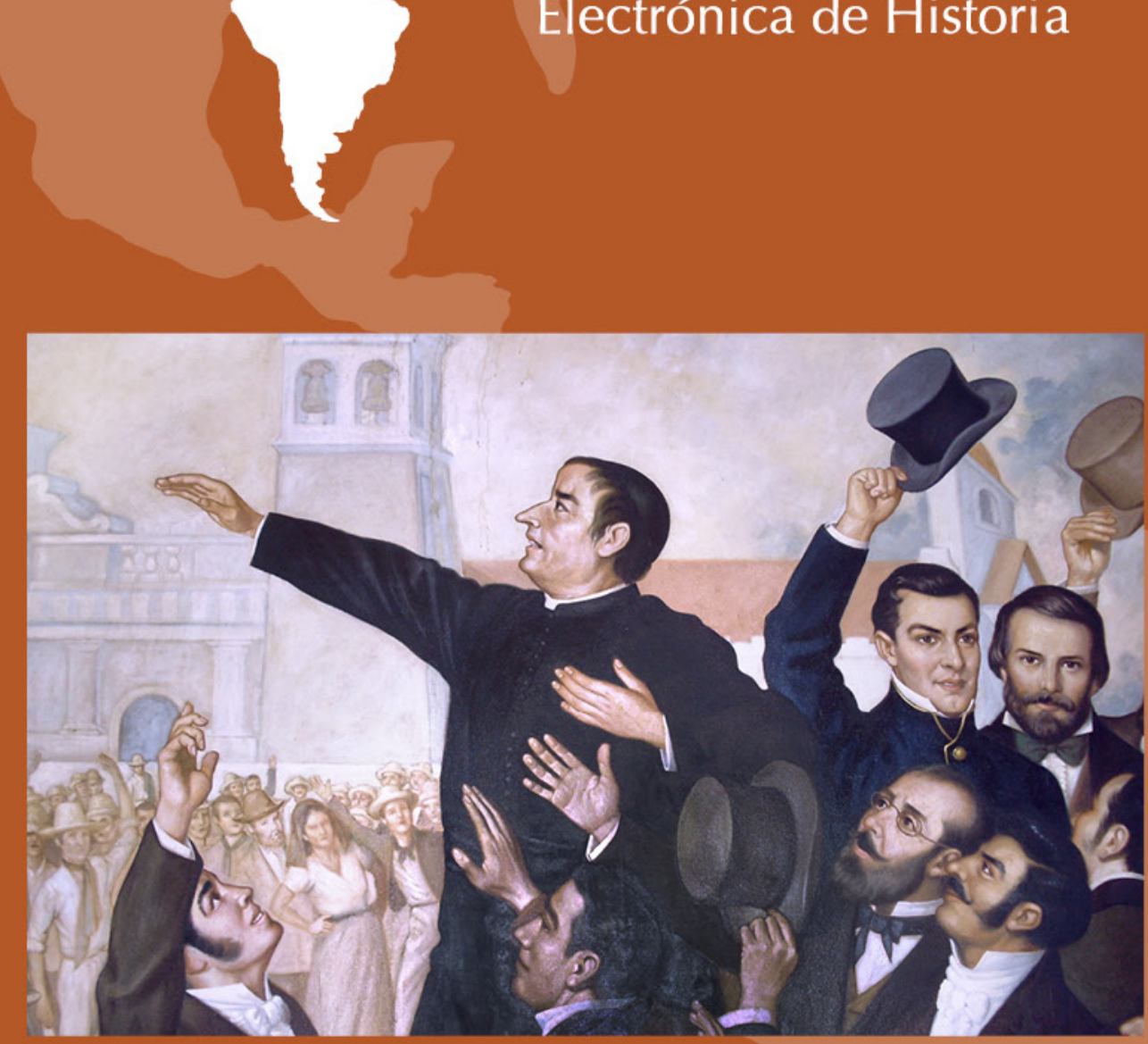

Centro de Investigaciones Históricas de América Central. Universidad de Costa Rica

\title{
Julio-diciembre 2021
}

url: http://revistas.ucr.ac.cr/index.php/dialogos/index

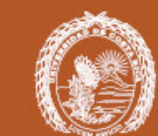

UNIVERSIDAD DE

COSTARICA

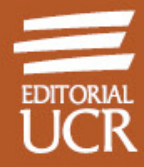




\title{
LA CONSTRUCCIÓN DE LA NORMALIDAD SEXUAL EN COSTA RICA ENTRE 1930-1950
}

\author{
José Daniel Jiménez Bolaños
}

\begin{abstract}
Resumen
Este artículo tiene por objetivo identificar los discursos científicos, educativos y mediáticos - presentes en un corpus de textos de la época - entre cuyos ejes se encuentra la normalidad sexual y, de esta forma, analizar algunos de los principales procesos históricos que conformaron la noción de la heterosexualidad en Costa Rica entre las décadas de 1930-1950. Mediante una revisión de manuales, investigaciones y artículos periodísticos, se establece que la construcción de la normalidad sexual estuvo influenciada por los saberes sexológicos, psicoanalíticos e higienistas, y se caracterizó por su carácter inestable, precario y contradictorio. Asimismo, dicho proceso de construcción produjo la conformación de sus amenazas. Se concluye que la normalidad, además de su carácter disciplinario, también tuvo un papel importante en la conformación de subjetividades, al entrar paulatinamente en el imaginario de la cultura popular.
\end{abstract}

Palabras clave: sexualidad, educación sexual, higiene, discurso, homosexuales.

\section{THE CONSTRUCTION OF SEXUAL NORMALITY IN COSTA RICA BETWEEN 1930-1950}

\begin{abstract}
This article aims to identify the scientific, educational, and media discourses - present in a corpus of texts of the time - among whose main axes is sexual normality and, in this way, analyze some of the main historical processes that made up the notion of heterosexuality in Costa Rica between the 1930s and 1950s. Through a review of manuals, investigations, and journalistic articles, it is established that the construction of sexual normality was influenced by sexological, psychoanalytic, and hygienic knowledge, and was characterized by its unstable, precarious, and contradictory character. Likewise, said construction process produced the conformation of its threats. It is concluded that normality, in addition to its disciplinary nature, also played an important role in shaping subjectivities, gradually entering the imaginary of popular culture.
\end{abstract}

Keywords: sexuality, sex education, hygiene, speeches, homosexuals. 


\section{INTRODUCCIÓN}

En la época contemporánea, la idea de lo normal está tan profundamente enraizada en el discurso que resulta complejo problematizarla. Lo normal hace alusión a lo común, lo ordinario, lo usual, lo convencional y lo regular (Cryle y Stephens, 2017). Aunque en la academia se ha prestado atención a los efectos que esta idea produce en la vida de aquellos sectores de la población catalogados como anormales, desviados o patológicos (Flores, 2007; Gamboa, 2009; Arias, 2016) es poco lo que se ha analizado sobre la construcción misma de la normalidad en el contexto costarricense.

A finales del siglo XIX, lo normal mantenía las connotaciones que había adquirido desde 1820, un término especializado del discurso médico que se refería a la condición de salud y funcionalidad biológica general. En la segunda mitad del XIX, la palabra normal empezó a aparecer en los diccionarios anglófonos y europeos, y hacia finales de ese siglo dicha palabra adquirió una centralidad conceptual, siendo utilizada con mayor frecuencia en los incipientes estudios sobre la sexualidad humana (Cryle y Stephens, 2017).

Paralelamente, el interés científico por los temas relacionados con la sexualidad empezó a cristalizarse a finales del siglo XIX en algunas regiones de Europa, a través de la sexología, el psicoanálisis y, más tardíamente, la higiene y la salud pública. ${ }^{1}$ Como afirma Weeks (2012), lo que constituyó la originalidad y significancia de la recién creada sexología no fue tanto su objeto de estudio, sino, más bien, la dirección y el camino que siguió el trabajo. El punto más significativo era la premisa de que la sexualidad merecía estudios serios, no solo por sus componentes fisiológicos vinculados con la salud y la enfermedad, sino por su importancia para la conformación de la existencia de los individuos y la sociedad (p. 184).

La sexología exploraba un nuevo continente de conocimientos y simultáneamente asignaba una nueva significancia a lo sexual dentro del ámbito social y psíquico. Empezaron a reemplazarse viejas categorías ambiguas por nuevas clasificaciones médicas y psicológicas. Inicialmente, mucho del interés sexológico se volcó al análisis de todos aquellos aspectos que se alejaban de la "norma", sin embargo, ese trabajo de definir y explicar lo "anormal" también tuvo el efecto de clasificar y conceptualizar de forma más detallada lo que constituía "lo normal" (Weeks, 2012).

Los estudios médicos y científicos sobre la sexualidad humana producidos entre 1870 y 1930 constituyen un momento crucial en la genealogía de lo normal, ya que ampliaron los parámetros conceptuales del término, y catalizaron el tránsito de un uso exclusivamente profesional y médico, a uno más anclado en la cultura popular (Cryle y Stephens, 2017).

Estas nuevas formas de ver lo sexual empezaron a tener cierta influencia en el contexto costarricense. Por ejemplo, muchas de las bibliotecas pertenecientes al sistema de la Secretaria de Instrucción Pública, adquirieron tratados sexológicos, manuales de higiene y libros de autores tan representativos como Sigmund Freud (Costa Rica, 1928, p. 608; Costa Rica, 1939, p. 292). De igual manera, Juan José Marín (2002) ha explicado ampliamente la dinámica donde, por medio de conferencias médicas y folletos 
escolares y colegiales, se dio una divulgación de materiales que buscaban "civilizar" a los sectores populares. Las cartillas higiénicas "cumplieron la función importante, en la difusión de la ideología liberal terapéutica” (p. 2).

En la primera mitad del siglo XX hubo una amplia circulación de manuales y revistas médicas que tenían por objetivo establecer pautas de comportamiento adecuadas en las relaciones conyugales, promover una mejor higiene sexual, y regular la dinámica de la prostitución. Las cartillas higiénicas "retomaron los enunciados básicos de los eruditos europeos; pero amoldándolos a la realidad del proyecto liberal-terapéutico costarricense" (Marín, 2002, p. 24).

En este afán de “civilizar”, los médicos e higienistas ${ }^{2}$ hicieron uso de varios de los planteamientos sexológicos y psicoanalíticos que se habían venido construyendo en algunas regiones de Europa desde finales del siglo XIX. Se tenía una noción de la realidad social como desordenada, peligrosa y antihigiénica, y los actores sociales populares - junto a sus costumbres - eran visualizados como "incivilizados, toscos, groseros y, en algunos casos, depravados" (Marín, 2002, p. 39). Este poder de enunciación que tenían los sectores médicos no surgió espontáneamente; fue el resultado de un proceso paulatino de institucionalización de la medicina en el país. Proceso que en el siglo XIX empieza a consolidarse con la creación de varias instituciones vinculadas a la salud pública, la persecución de prácticas medicinales populares y la instauración de un cierto control social, con la Iglesia y la Policía como agentes fundamentales, además de otra gran cantidad de actores sociales involucrados (Marín, 2000).

Este proceso enunciativo por parte del sector médico se desarrolló en conjunto con varios de los ideales que formaban parte de la base ideológica del liberalismo costarricense. Bajo esta perspectiva, algunos intelectuales liberales se dieron a la tarea de interpretar el concepto de raza, y empezaron a adoptar los planteamientos del darwinismo social: el resultado de este maridaje fue la idea de la población costarricense como una raza homogénea que debía ser protegida (Palmer, 1996, pp. 100-106). Al mismo tiempo, la influencia del higienismo también estuvo presente en el sistema educativo, al menos desde 1920; en instituciones como la Escuela Normal, el Liceo de Alajuela y el Colegio Superior de Señoritas se dieron esfuerzos por colocar la educación sexual, la higiene y el venerismo como parte del currículum educativo (Molina, 2019).

De acuerdo con lo anterior, es posible afirmar que, en la primera mitad del siglo $\mathrm{XX}$, se vislumbra un proceso de construcción de la normalidad sexual, el cual es materializado a través de todos aquellos elementos que buscaban guiar el comportamiento entre personas de distinto sexo: manuales, guías y tratados médicos. Algunos de estos manuales fueron escritos por médicos e higienistas, quienes - en un contexto de circulación de saberes y posturas ideológicas - colocaron a las dinámicas relacionales vinculadas con la heterosexualidad como un "problema” que había que atender. Por lo tanto, este artículo tiene por objetivo identificar los diferentes discursos científicos, educativos y mediáticos ${ }^{3}$ - presentes en un corpus de textos de la época - entre cuyos ejes centrales estaba la normalidad sexual y, de esta forma, analizar algunos de los principales procesos que conformaron la noción de la heterosexualidad en Costa Rica entre las décadas de 1930-1950. 


\section{"LA SOLUCIÓN DEL PROBLEMA DE LAS RELACIONES ENTRE VARÓN Y MUJER": REGULACIÓN CONYUGAL, EUGENESIA E HIGIENISMO}

En la primera mitad del siglo XX todavía existía una cierta incertidumbre en torno a las bases biológicas, químicas y orgánicas de los mecanismos de la sexualidad, por lo que no se podía más que especular acerca de las posible razones y motivos de que los hombres y las mujeres se comportaran de cierta manera. Con el desarrollo de la medicina, la psiquiatría, la sexología y el psicoanálisis, estas incertidumbres empezaron a ser abordadas científicamente, promoviendo una "verdad" (Foucault, 1999) sobre la normalidad sexual que, como se concluye en este artículo, se trató siempre de una "verdad" precaria, sostenida con bases endebles y siempre abierta a contradicciones y paradojas.

Uno de los médicos que participó en las discusiones en torno a la normalidad sexual a inicios del siglo XX fue Carlos Pupo Pérez quien, siendo médico y director del Banco Nacional de Seguros, experto en bacteriología y funcionario del Hospital San Juan de Dios, publicó en 1935 un libro titulado Nuestros males. Principios sanitarios que nadie debe ignorar (1953). Dicho texto es prototípico de las cartillas higienistas que se divulgaron en Costa Rica durante esos años, el cual abordaba una gran cantidad de temáticas relacionadas con los comportamientos de la población.

En el capítulo que atañe a los comportamientos sexuales, el Dr. Pupo afirma que, desde la antigüedad, lo sexual siempre ha sido tratado con un cierto encubrimiento, lo cual provocaba que el sexo se convierta en un misterio impenetrable. Además, manifiesta que, en los pueblos primitivos, existía una gran ignorancia en torno a la procreación y que dicha ignorancia había que eliminarla, dándole toda la información necesaria a los niños desde muy temprana edad. Posiblemente, influenciado por el psicoanálisis freudiano, Pupo defiende la aparición del instinto sexual aparece desde la infancia, y que la masturbación era inofensiva (Pupo, 1936).

Una de las técnicas utilizadas por la sexología en sus primeros momentos fue la comparación del comportamiento humano con el animal. En el libro, Pupo establece que el comportamiento sexual del hombre puede comprenderse mejor cuando se conoce el de otros animales, como el mono. Pupo afirma que "el chimpancé medio cansado sexualmente, deja tranquila a su compañera habitual; pero si le presentan a una nueva, y más si es joven y bonita, da muestras inequívocas de excitación sexual. Conducta similar se observa en los humanos con dramas imposibles en el mundo de los simios" (Pupo, 1936, p. 417).

La idea de asignar cualidades humanas a los animales como forma de comprender los mecanismos de la sexualidad es una de las estrategias implementadas en los discursos que buscan construir y regular la normalidad sexual. El corolario de este argumento es la cuestión de la monogamia y el "animalesco instinto" de los hombres por tener relaciones sexuales con muchas mujeres. En ese sentido, Pupo declara que "si a ciertos individuos les gustan todas las mujeres, menos la propia, 
en cambio hay otros con tendencias monogámicas muy acentuadas, ya sea por la completa e irremplazable compatibilidad sexual de la contraparte, por los frenos que imponen las conveniencias personales" (Pupo, 1936, p. 417).

Detrás de todas estas argumentaciones está la necesidad de que tanto el hombre como la mujer formalicen su relación y comprendan el conjunto de reglas y procedimientos para llevar a cabo un matrimonio exitoso. Desde la perspectiva del médico, existía una gran incertidumbre en torno a las bases del amor, no obstante, deja entrever posibles hipótesis de su formulación química y hormonal, para luego manifestar que "el amor es y será, la única base popular y estable para la unión entre hombres y mujeres; sus leyes - y sin duda las tiene - son desconocidas; nadie lo manda ni lo gobierna" (Pupo, 1936, p. 423).

Lo interesante de este texto radica en el hecho de que coloca a las relaciones entre hombre y mujer como un problema sanitario que debe ser atendido; la práctica heterosexual no cuenta - por sí sola - con la aprobación social innata, sino que debía ajustarse a ciertos principios higiénicos y cumplir ciertas características, de otra forma, quedaría al mismo nivel que el acto sexual entre animales. ${ }^{4}$ Por lo tanto, además del amor, se abordan otros temas como la educación sexual, la prostitución y las enfermedades venéreas (Pupo, 1936, pp.417-432). A lo largo de gran parte de estas discusiones sexológicas, la idea del amor - y del amor romántico específicamente - va a ser un eje discursivo fundamental; el procesos de construcción de la heterosexualidad se va a servir del amor como manera de diferenciarse del "otro amenazante".

Otro de los médicos que tuvo un papel importante en estas manifestaciones de construcción de la normalidad sexual es el Dr. Pablo Luros Floru, quien, durante la década de 1930 y 1940, laboró en el Departamento de Estadística Vital y Educación Sanitaria de la Secretaría de Salubridad Pública; además, se desempeñó como asesor de la Organización y Administración Hospitalaria de la Junta de Protección Social de San José entre 1954 y 1958, así como profesor de griego en la Universidad de Costa Rica. El Dr. Luros publicó varios libros y folletos sobre temas tan diversos como la educación, la economía y la moral (Láscaris, s.f. pp. 355-358). Sin embargo, su foco de atención principal fue la sexualidad y el matrimonio.

En uno de sus libros publicado en 1941 titulado El sentido de la vida, Luros establecía una serie de pautas para que el hombre lograra obtener un correcto programa de vida y felicidad. Por medio de argumentos de base psicológica, afirmaba que el malestar del hombre y la búsqueda del sentido de la vida se podía resumir en tres cuestiones: la relación del sujeto con el mundo material, con otros hombres, y con el otro sexo.

Sobre la tercera cuestión, se dice que "el hallazgo de las relaciones correctas con el otro sexo se enfrenta por el hecho biológico de que la función de la reproducción se opera con dos individuos (...) Cada individuo, hacia la época de la excitación del instinto sexual, deberá hacerse cargo del problema y tratar de resolverlo" (Luros, 1941,p. 11). El mismo Luros llama a este problema la relación sujeto - heterosexual, y lo coloca como uno de los grandes aspectos que deben ser resueltos para encontrar el adecuado sentido de la vida. Aunque, en un inicio, plantea que para encontrar 
dicha solución hay que partir de que la unión entre ambos sexos es una función básica para la supervivencia del ser humano, rápidamente pasa a problematizar dicha noción a partir de la idea del matrimonio. Con relación a esto afirma que:

\begin{abstract}
La sociedad, con el matrimonio, desde tiempos muy remotos, se esforzó en dar una solución a este problema. Se considera, pues, que el matrimonio es el único aspecto de la unión sexual permitido por la sociedad; ésta no reconoce las uniones extramatrimoniales. Pero la unión de los dos sexos por medio del matrimonio, ¿puede considerarse como las más adecuada? La situación, a veces, de familias de ricos, así como de pobres que viven casi en disolución, demuestra que este aspecto de la solución del problema no es la debida. No basta con que dos seres humanos convivan, para aceptar que son uña y carne en el matrimonio. Para que esa convivencia humana de dos individuos sea armoniosa, y pueda así cumplirse con la misión impuesta y debida, será menester una particular disposición psíquica del uno frente al otro sexo. Cuál debe ser esa disposición psíquica, es lo que, principalmente constituye el problema que debe solucionarse. El hecho matrimonial, o el de cualquiera otra unión, es simplemente un fenómeno externo; puede ser varia [sic] la forma de esa unión sin que se obstaculice la solución del problema, bastará con que la actitud psíquica del uno frente al otro sexo sea la debida. (Luros, 1941, p. 11-12)
\end{abstract}

Primeramente, se menciona que una de las maneras más usuales con las que se ha tratado de resolver el "problema" de la heterosexualidad ha sido con el matrimonio. Sin embargo, Luros inmediatamente establece que dicha solución no siempre es la adecuada y afirma que la solución se encuentra en algún lugar del universo psíquico de las personas. En contracorriente de las posturas tradicionales que colocaban al hombre y a la mujer en roles separados, uno por encima del otro, Luros afirma que, para que dicha disposición psíquica sea la adecuada, "el hombre debe presentarse a la mujer como de igual a igual (...) como colaborador en una obra común" (Luros, 1941, p. 14). Al apelar a la mujer, también establece que "no debe considerarse a sí misma inferior al hombre (...) en la convivencia de los sexos deberá buscarse la abnegación irrestricta y desinteresada del uno por el otro, y tomar valientemente la responsabilidad de las consecuencias de la unión" (Luros, 1941, p. 11).

Lo anterior permite ver que la perspectiva de Luros es disruptiva en el contexto patriarcal de la sociedad costarricense de inicios de la década de 1940, donde pese a la lucha de mujeres, no se había aprobado el voto femenino y estas - por ejemplo - seguían siendo consideradas seres inferiores e incapaces de tomar decisiones políticas (Rodríguez, 2008).

Según Luros, esta situación desequilibrada entre las mujeres que sufrían opresión y los hombres que contaban con una posición privilegiada, daba paso a una lucha entre los sexos, la cual "hace imposible la que debe ser la solución del problema de las relaciones entre varón y mujer (...) es necesario que desaparezca esta lucha y prevalezca el amor, la confianza mutua, la cooperación y la solidaridad" (Luros, 1941, p. 15). En opinión de Luros, usualmente son los individuos con algún tipo de trastorno mental los que del todo no lograban solucionar las tres cuestiones del sentido de la vida y, basándose en investigaciones psicológicas, 
concluía que más allá de los sujetos, había pueblos enteros que habían sufrido por no resolver estas problemáticas descritas, "no han logrado regularizar sus relaciones con los otros pueblos, resolver el problema económico y el de sus relaciones con el otro sexo" (Luros, 1941, p. 16).

Los planteamientos de este médico evidencian, una vez más, que la heterosexualidad vista como una institución social y como un régimen político de organización del deseo (Tin, 2012; Adams, 2012; Guasch, 2000; Katz, 2012), era interpretada en términos de un problema que había que resolver. Se trata de un discurso médico-científico que no consideraba suficiente que el hombre y la mujer se unieran; para que dicha unión fuera "adecuada”, tenía que cumplir ciertos requisitos y contar con una serie de características. De lo anterior se desprende que el tema del matrimonio ocupara un lugar primordial en estas discusiones.

En este proceso de construcción de la normalidad sexual, la dinámica relacional entre hombres y mujeres, además de estar mediada, obligatoriamente, por el amor, tenía que adecuarse a una serie de requerimientos. Por lo tanto, se trata de un proyecto que regulaba no solamente los comportamientos, sino que también producía los sujetos a los que estaba haciendo referencia en el mismo momento de su enunciación, la normalidad no se reduce a su capacidad disciplinaria, es también productora de subjetividades.

Investigar el alcance que tuvo la difusión de estos textos es complicado. Según lo planteado por Marín (2002), muchas de las cartillas higiénicas eran leídas por profesores, alumnos, jóvenes y parejas adultas, los tirajes posiblemente oscilaban entre las 1500 y las 3000 copias (pp. 20-29). Además, hay que considerar el hecho de que estos autores también eran vistos como parte importante del mundo intelectual costarricense de la época, al ocupar puestos políticos o administrativos de gran transcendencia, por lo que tenían una mayor capacidad para difundir sus ideas y un público anuente a escucharlos. En gran parte, fue gracias a estos escritos - enmarcados en un contexto de propagación de saberes en torno a la higiene- que la idea de la normalidad sexual experimentó su tránsito desde los discursos médico-científicos a una concepción más popular.

La publicación - en diferentes partes del mundo - de manuales sobre el matrimonio fue algo muy común en la primera mitad del siglo XX. Aunque se podría argumentar que la familia y el matrimonio son instituciones con muchos problemas asociados a los vínculos entre sus integrantes desde hace mucho tiempo, no es hasta finales del siglo XIX e inicios del XX que se desarrolla un interés médico-científico sistemático por atender estas temáticas.

Era necesario publicar guías, manuales y documentos de ayuda para hacerle saber a las mujeres y a los hombres - principalmente de extracto popular - cuáles eran las actitudes y prácticas más recomendadas para encontrar una cierta armonía en su unión. El mismo doctor Luros publicó en 1939 un manual titulado Salud y matrimonio, en el cual se abordan una serie de aspectos que, de cierta forma, buscaban regular el comportamiento heterosexual conyugal. 
En el prólogo de dicho manual, el Dr. A. Peña Chavarría ahondaba en los atestados de Luros y mencionaba los principales aportes de la obra. Peña afirmaba que el trabajo de Luros era fundamental, ya que tenía por objetivo elevar la cultura sanitaria del país y "resaltar las reglas eugenésicas que regulan el equilibrio y la armonía dentro del matrimonio" (Luros, 1939, p. 5). Al basarse en las premisas del manual, Peña consideraba que el matrimonio "influye en la patología de los sexos, tiene estrecha relación con la demografía (...) influye en la salud corporal y psíquica de los individuos" (Luros, 1939, p. 4). Por lo tanto, desde el mismo prólogo queda de manifiesto, explícitamente, el trasfondo eugenésico del documento.

En el manual se comienza con la afirmación de que el matrimonio forma parte de los aspectos más importantes de la higiene, cuyas implicaciones van más allá de los individuos involucrados, ya que dependiendo de la forma en que se lleve a cabo, la conformación de "buenos matrimonios" permitiría eventualmente "la creación de una raza costarricense moral, sana y vigorosa" (Luros, 1939, p. 8). Como ya se vio anteriormente, la composición racial de la población era una preocupación política y social que venía en desarrollo desde el siglo XIX en el país, y que, en ocasiones, había desembocado en legislaciones discriminatorias y racistas (Palmer, 1996).

Por lo tanto, era necesario proteger al matrimonio, lograr que sus usos y costumbres se adaptaran a dicho fin eugenésico; el argumento de Luros era muy claro: "la vida familiar es la fortaleza más segura contra la decadencia de la moral. Y que la vida de familia conservando el hogar, conserva también al Estado. El Estado no puede existir sin familia. El matrimonio es el barómetro de la sociedad" (Luros, 1939, p. 11). De igual manera, "es el preventivo y curativo de los vicios y pasiones que arruinan la salud, que ahogan la consciencia, que trastornan el espíritu y que conducen al suicidio o a la locura" (Luros, 1939,p. 11), para luego establecer que el matrimonio "fue, es y se cree que seguirá siendo el mejor, el más saludable y el medio más recomendable para la satisfacción y la regulación de la vida sexual" (Luros, 1939, p. 13).

La pareja del hombre y la mujer se volvía, bajo esta óptica, en un escudo, una barrera de primera línea que tenía la capacidad de evitar que la sociedad como un todo se desviara por rumbos "inadecuados". Además, se le daba al matrimonio propiedades terapéuticas y curativas, al vincular directamente la acción de casarse como un medio para prevenir enfermedades mentales, e incluso los crímenes. Para justificar dichas afirmaciones, Luros mencionaba las estadísticas penales de Costa Rica, así como los expedientes de ingreso en el Asilo Chapuí; para ambos casos, los solteros parecían tener una mayor predisposición a la psicosis, al suicidio y a la criminalidad. Asimismo, se manifestaba que los hijos ilegítimos provocaban la "degeneración" moral y contaban con menos vitalidad que los hijos nacidos dentro del matrimonio (Luros, 1939, pp. 13-20). Las metáforas biológicas y militares fueron una de las estrategias discursivas más frecuentes en este tipo de publicaciones.

En la segunda parte del manual, Luros aborda diferentes aspectos vinculados con la conformación de la pareja y la escogencia del cónyuge, por ejemplo, la cuestión etaria. En el manual se manifiesta que cuando la mujer es menor de 19 años y el 
hombre menor de 24 el matrimonio "no sólo es ilógico y antihigiénico, sino que es peligroso para los que lo contraen" (Luros, 1939, p. 25). Los posibles hijos de estos matrimonios prematuros eran caracterizados detalladamente "de calidad corporal y psíquica inferior, enfermizos, pequeños de cuerpo, linfáticos, mal desarrollados y no raras veces idiotas" (Luros, 1939, p. 26).

De igual manera, los matrimonios en edad avanzada también eran vistos como perjudiciales, ya que la edad de los padres muy adultos "predispone a los hijos a la debilidad corporal y moral, a la degeneración, y con frecuencia a algunas enfermedades psíquicas" (Luros, 1939, p. 28). Finalmente, los matrimonios en donde la edad de los cónyuges presenta una desproporción de años, eran vistos como los más censurables de todos, de estos se afirmaba que "son contrarios a las leyes fisiológicas y terminan en el fracaso. Una gran desproporción en la edad de los cónyuges es factor importante en la etiología de los matrimonios desgraciados" (Luros, 1939, p. 29). Claramente, el matrimonio por sí solo no era suficiente para promover una buena relación de pareja, el aspecto etario era fundamental. Desde estos discursos, una medida para saber si un matrimonio era "adecuado" o no, se basaba en las características de la descendencia. De esta forma, la perspectiva sexológica y la eugenésica se acercan, se influencian mutuamente y crean vínculos discursivos, además de que construyen toda una categorización de los sujetos saludables.

Junto a las cuestiones etarias en la escogencia de pareja, había otra serie de elementos que se tenían que considerar para poder tener una familia "sana". Para Luros era importante que, con las escogencias matrimoniales, desaparecieran las viejas manchas familiares y se regenerara la raza costarricense. Por ejemplo, para la escogencia de una esposa, se podían seguir estas reglas:

Para que una joven pueda ser esposa abnegada y madre perfecta, debe poseer requisitos corporales, morales y espirituales. Como requisitos corporales mencionamos: salud individual y hereditaria satisfactorias, formación armoniosa, elegancia de formas, regularidad de cara, cabello hermoso y abundante, estatura mediana, busto bien desarrollado, cintura no muy estrecha. Como requisitos morales e intelectuales los más recomendables son: la inteligencia, la bondad, la dulzura, la buena educación familiar. (Luros, 1939, p. 43)

De igual manera, para los hombres también había que cumplir ciertos requisitos, tanto físicos como morales e intelectuales. Una vez más, queda evidenciada la premisa sexológica, en donde la construcción de la normalidad sexual debe regirse por estrictos mecanismos y bajo la tutela de expertos. Se pensaba que la elección del cónyuge ideal no podía quedar en manos del azar o el libre albedrío, tenía que regirse por atributos específicos y regulados, guiados por la higiene. Esta primera etapa del matrimonio era visualizada como una de las más complicadas, ya que, muchas veces, los matrimonios no lograban una verdadera armonía y terminaban en separación. De esta forma, se perfilan y adquieren forma las características que deben tener los sujetos para acoplarse de forma "adecuada" junto a alguien del sexo opuesto. 
Una vez que se había efectuado el casamiento, había instrucciones y pasos a seguir para la vida en familia. Uno de los aspectos finales del manual tiene que ver con el acto de la procreación, el cual, al igual que con la escogencia del cónyuge, debía "ser consciente y seguida por todas las garantías higiénicas y eugenésicas" (Luros, 1939, p. 45).

En el manual se afirma que, para poder heredarle a los hijos los mejores atributos y protegerlos de la herencia de los defectos, era necesario que el acto sexual se llevara a cabo en "el momento en que sus defectos no se encuentren en intensidad por razón de cansancio, de ingestión alcohólica o alguna enfermedad, y sus virtudes se encuentren intensificadas con la vida higiénica y tranquila y el ejercicio corporal" (Luros, 1939, p. 48). De igual manera, se afirmaba que "la concepción hecha en momentos de cólera, de emoción, de dolor psíquico, de embriaguez, de enfermedad, de convalecencia, de debilidad, etc., comporta frutos imperfectos, atrofiados y anormales" (Luros, 1939, p. 49). Una vez más, se mide la validez de la unión por las características de la descendencia y se establecen pautas a seguir para el momento del acto sexual procreativo, en las cuales se evidencia una mezcla de saberse médicos y suposiciones populares. El qué, el cómo, el cuándo y el con quién del acto sexual heterosexual era algo altamente regulado en estos discursos.

Este manual, que se publicó en 1939, es una evidencia de los principales elementos que formaron parte del discurso médico sexológico y su proyecto de construcción de la normalidad, durante la primera mitad del siglo XX. En él se vislumbra de forma detallada toda una pedagogía de la heterosexualidad; es decir, una serie de lineamientos que se deben enseñar y cumplir para ser considerados saludables y, por lo tanto, normales. En ese mismo contexto, se creó mediante decreto ejecutivo en 1943 la Liga Social Antivenérea, la cual tenía por objetivo elevar la salud de la población, disminuir las tasas de mortalidad infantil y "obtener que nuestra raza sea más fuerte, más sana y, potencialmente fecunda" (Amador, 1946, p. 13), además de "velar por la salud del futuro niño, controlando la de sus padres, a fin de evitar que aquél vaya a aumentar las filas de esos desdichados que pueblan los asilos, cárceles y manicomios de nuestra Costa Rica" (Amador, 1946, p. 11).

La búsqueda de una mejora en la raza costarricense fue uno de los principales ejes transversales que formaron parte del proceso de construcción de la normalidad sexual. En conjunto, estas cartillas higiénicas, tratados y manuales de comportamiento constituyeron un nuevo discurso público sobre el sexo, enmarcado dentro de las premisas del higienismo. El sexo era visto como un impulso natural y volátil que requería de supervisión estricta y de una pedagogía que estableciera la ruta que se debía seguir para alcanzar la normalidad. Esto produjo la necesidad de programas de educación que, de la mano con las autoridades de salud pública, le dieron a la normalidad una mayor autoridad cultural. 


\section{LA NORMALIDAD SEXUAL EN LAS AULAS}

La construcción del normalidad sexual no se desarrolló solamente a través de las publicaciones y discursos higienistas y científicos; el sistema educativo también funcionó como una plataforma para la propagación de ideas normativas en torno a los comportamientos sexuales. Desde 1920 es posible encontrar en las memorias institucionales de la Secretaría de Instrucción Pública, menciones acerca de la necesidad de implementar y fortalecer los contenidos sobre higiene sexual entre los temas abordados en las aulas.

Para 1929 se empieza a plantear un reglamento en los colegios de segunda enseñanza, el cual estaba dividido por capítulos donde se especificaban las funciones que tenían los diferentes integrantes de la estructura educativa. En el sector correspondiente a los médicos, se apuntaba que estos tenían como obligación "dictar a los alumnos conferencias sobre higiene y, en los cursos superiores de varones, especialmente sobre las funciones sexuales y el venerismo." (Costa Rica, 1929 , p.179). Un punto que va a ser retomado en 1939 en donde, como parte de una propuesta para revisar dicho reglamento, se establece exactamente lo mismo bajo la presidencia de León Cortés (Costa Rica, 1939, p.15).

Por lo tanto, los planes de estudio de segunda enseñanza prolongaron la temática de las cartillas higiénicas. Aunque es difícil determinar hasta qué punto dichos contenidos fueron efectivamente abordados en las aulas, el hecho de que se mencionen en las memorias institucionales da cuenta de que existía, al menos, la noción de su importancia y una cierta voluntad para implementar la materia dentro del currículum educativo.

Por ejemplo, en una carta escrita por José Fabio Garnier, quien fungía como director de la Escuela Normal en 1936, se explicaba el proyecto para confeccionar un plan de estudios de los normalistas a nivel de bachillerato. Específicamente para el tema de psicología, mencionaba que era importante que los bachilleres tuvieran un conocimiento amplio de psicología general e infantil. Asimismo, se establecía que no se debían olvidar todos aquellos temas vinculados con el adolescente "ni los que se refieren a los niños seudo-anormales y anormales; tampoco se creyó prudente ignorar las cuestiones de la Psicología sexual que son de interés fundamental para quien desea desempeñar con acierto las funciones docentes" (Costa Rica, 1936, p.91).

En un informe destinado para la Secretaría de Educación, la dirección del Colegio de Señoritas hacía constar que era necesario suplir ciertas faltas, entre ellas, mejorar el financiamiento y los salarios. En la carta se afirmaba que uno de los principales logros había sido el poder contar con servicios médicos permanentes y con un doctor que se encargara de atender todo tipo de enfermedades. Sin embargo, se mencionaba que todavía hacía falta un dentista, un oculista y algún servicio para prevenir los debilitamientos pulmonares. En la carta, el director de dicho colegio, Salvador Umaña, finalmente manifestaba que "no me atrevo a todavía sugerir alguna intervención en los problemas sexuales, que son tratados, pero indirectamente y en forma velada por las profesoras casadas" (Costa Rica, 1937, p.94). 
Por lo tanto, se puede argumentar que, por medio de las escasas menciones que se hace de la sexualidad en las memorias de la Secretaría de Educación Pública, se entrevé un contexto donde el tema no era completamente ajeno a la institucionalidad educativa urbana. No obstante, su presencia es bastante fragmentaria. Los rastros y las huellas de una apuesta estatal por fomentar este tipo de educación no son muy claras en estas primeras décadas del siglo XX. Las problemáticas que, eventualmente, llegan a manifestarse en el discurso están relacionadas principalmente con temas de higiene y prevención de enfermedades.

Bajo la presidencia de Rafael Ángel Calderón Guardia (1940-1944), se da una creciente influencia de la religión en la educación. El acercamiento de la política con la Iglesia Católica se vio cristalizado con la erradicación de las leyes liberales, las cuales habían puesto límites en el accionar público de la Iglesia desde la década de 1880, principalmente en el ámbito educativo (Díaz, 2010).

En una tesis universitaria elaborada en 1941 para obtener el grado de profesora en enseñanza primaria, la autora Julieta Guevara Dávila hizo un recorrido sobre el tema de la cuestión sexual en la escuela. Su tesis, la cual está escrita a mano y consta de 81 páginas, inicia con una conceptualización de lo que se entendía por educación sexual. En ese sentido, afirma que "es la orientación del niño frente al problema sexual, a fin de que pueda disciplinar su conducta, lográndose así una educación en general, sirviendo además de base para la preparación del hombre en la vida futura" (Guevara, 1941, p. 1). De manera explícita, se expone la necesidad de disciplinar y regular los actos y las conductas de los individuos desde una edad temprana, para orientar sus comportamientos. Además de que, en concordancia con las discusiones anteriores, se planteaba a la sexualidad como un "problema" que había que atender.

El debate sobre la relevancia de dar este tipo de educación a niños y niñas estaba escindido en dos posiciones generales. Por un lado, se argumentaba que los niños poseían una inocencia innata la cual debía cuidarse y, evitar exponerla a cualquier tipo de información sexual. Por otro lado, se establecía que los niños eran seres sexuales desde su nacimiento y, por lo tanto, su educación en este ámbito era una necesidad fundamental.

Esta segunda posición había adquirido mayor impulso gracias a la popularidad y distribución de los textos de Sigmund Freud, especialmente sus Tres ensayos para una teoría sexual, publicado originalmente en 1905. En la memoria institucional de la Secretaría de Educación Pública de 1939, se menciona que, en la biblioteca técnica de dicha institución, se habían adquirido varios libros de Freud, entre ellos Introducción al psicoanálisis; Una teoría sexual y otros ensayos; Psicopatología de la vida cotidiana; La interpretación de los sueños; Tótem y tabú; Inhibición, síntoma y angustia; El análisis profano y, Malestar en la cultura (Costa Rica, 1939, p. 292). Esto indica que sus libros ya eran conocidos y accesibles durante la década de 1940; posiblemente, los planteamientos de Freud llegaron a tener una cierta recepción por parte de diferentes sectores de la sociedad costarricense, especialmente los vinculados con el sector educativo. ${ }^{6}$ 
En ciertas partes de su tesis, Guevara Dávila hace mención explícita de algunas teorías psicoanalíticas. Asimismo, se menciona que, idealmente, la educación debería iniciar en los hogares en el momento en que los niños empiecen a hacer preguntas e interesarse por el tema. De esta forma, según la autora, se asimilarían los principales hechos sexuales de manera natural y, una vez que se ingresara al sistema educativo, ya el individuo conocería los temas fundamentales de la vida sexual, lo cual facilitaría la labor del maestro. Este último se representa como alguien que debe adoptar una actitud mesurada, sin anticiparse a la curiosidad del niño, eludiendo cualquier tipo de enseñanza innecesaria. La autora manifiesta que

\begin{abstract}
Es casualmente en el tiempo escolar, en donde el niño sufre sus primeros fenómenos sexuales e inquietudes, pudiendo decirse, que son dos las etapas de la edad escolar: la primera, es el periodo anterior a la pubertad. En este no debe intervenir la instrucción sistematizada, porque aún no es necesario. El maestro debe observar, se podría decir, con astucia, la conducta del niño para descubrir las posibles manifestaciones precoces de la sexualidad, y entonces es aquí indispensable la intervención de los padres, a fin de prevenir los malos hábitos. Una de las armas con las que puede contar el maestro en estos casos es su ascendiente moral sobre el alumno. Segundo: la época de pubertad y comienzo de la adolescencia. Esta ofrece un carácter diverso, porque los apremios sexuales se imponen y no es posible desconocerlos. Entonces las normas de higiene sexual son indispensables, lo mismo que la orientación moral. En resumen: se puede decir que es indispensable la educación sexual del niño, pero hay que saber dársela en forma inteligente y discreta a fin de evitar efectos contraproducentes. La vida sexual requiere preparación. Luego hay que educar al niño a fin de que adquiera las aptitudes necesarias para triunfar. Y, ¿cómo vamos a darle esos conocimientos al niño? Haciendo que todos los padres como los maestros sean educados en este sentido, que tengan un conocimiento amplio del problema y sepan educar a los niños. (Guevara, 1941, pp. 4-5)
\end{abstract}

El planteamiento de la tesis, el cual se evidencia de manera clara en el extracto anterior, señala la necesidad estratégica de iniciar la educación sexual, no con los niños directamente, sino con los padres y docentes, ya que, si no se instruye la estructura desde sus bases, sería muy difícil que la educación sexual fuera efectiva. Al mencionar las manifestaciones precoces de la sexualidad, la autora da a entender que hay ciertos comportamiento reservados para edades más avanzadas, lo cual denota una vez más la tensión discursiva en torno a la sexualidad infantil. Las metáforas militares surgen en el discurso, apuntan a la idea de que es necesario armar a los encargados de educar a los niños, para que puedan defenderlos de los malos hábitos. Esta perspectiva se construye a partir de la idea de la sexualidad como algo amenazante, pero inevitable, ya que sus apremios se "imponen.” Desde las primeras páginas de la tesis queda claro que, para una exitosa construcción de la normalidad sexual en las aulas, es necesario un esfuerzo coordinado que involucre a los adultos también.

De igual manera, a lo largo de la tesis de Guevara se hace mención constante a los “malos hábitos”, los cuales aparecen como fantasmas suspendidos a lo largo del proceso de instrucción sexual y que tienen el potencial de desviar las mentes y los cuerpos de los infantes. Estos malos hábitos se representan como todo aquello que se 
debe prevenir por medio de un ejercicio activo de la moral y la higiene. Una vez más, se conceptualiza a la normalidad sexual no solo como una problemática, sino como un proceso dificultoso, lleno de obstáculos, que requiere de constante vigilancia, regulación y preparación.

La canalización de la sexualidad es otro tema tratado por Guevara Dávila. En su descripción del concepto de instinto sexual, hace referencia a la existencia de una disposición "natural" que está dirigida a cumplir un conjunto de objetivos "útiles para la especie." Para la autora, basándose en algunos teóricos, el instinto era algo "innato", de esta forma "la atracción sexual es instintiva, pues es impuesta también por la naturaleza para la reproducción de la especie, y se traduce podría decirse en la afinidad que el individuo normal experimenta al sexo opuesto" (Guevara, 1941, p. 6). Lo "normal" aquí asume el papel de identificar aquello que produce el interés del hombre por la mujer y la mujer por el hombre, interés que es visto como un instinto canalizado y producido por los designios de la naturaleza, el cual paradójicamente está constantemente susceptible al desvío.

Desde finales del siglo XIX e inicios del XX, un objetivo común de la sexología era definir la esencia o la "verdad" de la sexualidad, materializada en el instinto sexual. El desarrollo de la biología y los estudios de Darwin estimularon un análisis de la clasificación de los instintos en términos puramente biológicos (Weeks, 2012).

Los planteamientos de Freud vienen a problematizar dicha visión sobre el "instinto", al proponer la pulsión, cuestionar al determinismo biológico y, agregar un fuerte componente simbólico, lo cual, a inicios del siglo XX, constituyó uno de sus argumentos más revolucionarios. Freud (1992b) establecía que la pulsión no tenía objeto definido, es decir, las pulsiones no estaban ligadas de manera automática a los objetos pulsionales, el instinto sexual no tenía un destino predeterminado.

Volviendo al argumento original que se hacía Guevara Dávila sobre el instinto sexual en el niño, la autora llegó a la conclusión de que este efectivamente existía. Sin embargo, hizo la acotación de que la atracción sexual aparecía sólo en la pubertad.

Los años de infancia y pubertad fueron tratados de forma amplia por la autora. Argumentaba que, antes de la pubertad, la vida sexual del niño se desarrollaba sin orientación o fin específico, todo constituye posible fuente de placer. Sin embargo, una vez en la pubertad "sus deseos se despiertan, el instinto se dispone como fuerza potente que lo lleva hacia el deseo despertado por el sexo opuesto. Y es aquí, donde vemos la importancia de esta edad, que fija el rumbo de la conducta sexual ulterior, por eso es indispensable orientarla hacia la normalidad" (Guevara, 1941, pp. 22-23 [énfasis añadido]).

De esta forma, para la autora, el interés por el sexo opuesto se alza como prueba de la existencia de madurez y de una orientación adecuada y normal del instinto. "Normalidad" que, no obstante, requiere ser encauzada desde los primeros años de vida y que necesita de guías y figuras de autoridad que se encarguen de disciplinar y rectificar cualquier tipo de desvío. La normalidad, en esta dinámica discursiva, no es algo que surge espontáneamente, sino algo que se alcanza después de pasar por etapas 
vitales peligrosas y delicadas. Para lograr eso, la autora plantea la necesidad de iniciar la educación sexual en la infancia, con el fin de evitar y superar dichas amenazas.

Guevara Dávila (1941) en varias ocasiones menciona las desviaciones del instinto y dedica gran parte de su tesis a explicar en qué consisten. Las define como "aquellas anomalías que nacen de una disposición pervertida del instinto y desarrollan en forma extraviada la perversión sexual" (p. 38). La autora divide estas desviaciones en dos tipos: las que no son comunes en la escuela, y las que sí lo son; en el primer grupo están el sadismo, el masoquismo, el fetichismo y el exhibicionismo.

En el segundo grupo están las que de manera más recurrente suceden en las aulas y, por ende, deben ser atendidas por los maestros, entre ellas la autora menciona a la masturbación, la cual es representada como un "vicio frecuente", un "hábito detestable" y muy difícil de extirpar y suprimir. Como consecuencia de la masturbación, se argumentaba que el niño era víctima de un agotamiento físico extremo, un agotamiento más poderoso que el acto sexual, ya que la "masturbación excita en forma ficticia y exagerada, al estar el estímulo natural reemplazado por un esfuerzo imaginario y por lo tanto artificial" (Guevara, 1941, p. 44).

El tema de la masturbación, u onanismo como en algunas ocasiones era llamada, tiene una larga historia en donde se mezclan concepciones morales, legales, religiosas y de salud pública. Entre finales del siglo XIX e inicios del XX, la mayor parte de los médicos alrededor del mundo empezaron a dejar atrás la idea de que la masturbación mataba, mutilaba o enloquecía a sus practicantes. Hacia 1930 empezó a asentarse la idea - dentro de los círculos médicos especializados - de que el sexo solitario era médicamente benigno (Laqueur, 2007). Dicho cambio en la posición del discurso médico no provocó que la noción culturalmente negativa hacia la masturbación dejara de existir, solo que ahora el miedo a la afectación física empezaba a ser reemplazado por un sentimiento de culpa.?

La tesis de Guevara Dávila y sus planteamientos se encuentran en un punto intermedio, donde todavía persiste algo de ambas nociones. Es aquí donde se empiezan a conformar los elementos que se considerarían amenazantes para la "normalidad." La masturbación es directamente problemática para la heterosexualidad porque va de la mano con el narcicismo, con tomarse a uno mismo como objeto sexual y, por ende, también con el homo-mismo-erotismo. Entonces, pone en riesgo al supuesto "instinto natural", porque cuestiona la necesidad del encuentro con el otro, y la supuesta obligatoriedad de la conformación de la pareja heterosexual. De esta forma, la masturbación se consolida como una de las amenazas de la heterosexualidad, por su capacidad disruptiva en el encauce "normal" del instinto. Seguidamente, la autora pasa a mencionar el segundo vicio común en las aulas, al afirmar que:

Después de la masturbación, el gran problema existente en la escuela es el homosexualismo. Y es muy natural, pues sabemos que el instinto sexual está en trance de madurez y al no hallar facilidad para ejercitarse en sentido heterosexual, da cabida a las manifestaciones homosexuales. Por otra parte, es frecuente que los niños incurran en estas prácticas, siguiendo el ejemplo 
de individuos viciosos o degenerados. Sabido es que los invertidos buscan casi siempre para satisfacer sus deseos, la inexperiencia de los niños. Hay que recordar, sin embargo, que fuera de los niños que cometen este vicio por extravío de la conducta pudiera decirse, hay otro grupo de niños degenerados por disposición congénita, desde luego estos son víctimas de este vicio sin ninguna culpa. (Guevara, 1941, p. 48)

La infancia, al ser representada como un proceso de transición, conlleva el potencial latente de verse corrompida, en ese proceso, el "instinto natural" se ve amenazado por las manifestaciones homosexuales. También es evidente el conjunto de significantes con los cuales se describe a los supuestos homosexuales: degenerados, viciosos e invertidos, lo cual denota una mezcla de visiones biológicas, morales e, incluso penales. ${ }^{8}$

En general, el tema de la masturbación se vio normalizado mucho antes que el de la homosexualidad. Algunos autores interpretan esto como la primera victoria contra el moralismo victoriano. En ese sentido, una hipótesis interesante que ha planteado Jean Allouch (2003) consiste en que el nuevo dispositivo de sexualidad, el cual se pone de relieve de forma progresiva después de la derrota frente a la masturbación, es el que construye la oposición entre lo heterosexual/normal, por un lado, y la homosexualidad/perversión por otro.

En la tesis de Guevara Dávila tanto la homosexualidad como la masturbación se instauran en un mismo nivel, ambas son vicios que se deben combatir desde la escuela por medio de la educación sexual. El sentido heterosexual del instinto debe ser encauzado y regulado de forma estricta. Al igual que la masturbación, la homosexualidad también se constituye como una de las amenazas para la normalidad sexual, ya que evidencian la paradoja de tener que enseñar el "instinto natural", poniendo en jaque su supuesta "naturalidad".

De acuerdo con la cita anterior, se menciona que, además de los niños que por un "extravío de la conducta" caen en un comportamiento homosexual, hay otros que se encuentran predeterminados por alguna fuerza natural que los lleva a comportarse de esa manera. Sobre el segundo grupo, la autora llama al fenómeno "hermafroditismo", y lo conceptualiza como una condición intersexual, donde se da un desarrollo paralelo de los dos sexos y, como consecuencia, hay una atracción erótica hacia su propio sexo. En conclusión "este viene a ser el invertido congénito, reconocido por su aspecto intersexual. Es decir, si es hombre ofrece aspecto femenino, y si es mujer, apariencia varonil. En estos casos lo recomendable es la canalización del instinto mediante una labor educativa cuyas normas indicará el médico" (Guevara, 1941, p. 50).

De esta manera, queda conformada la tríada masturbación - homosexualidad - hermafroditismo, la cual se erige como la estructura amenazante para la normalidad sexual, como aquello que evidencia - en el sentido más amplio - el gusto por lo mismo y que, simultáneamente, provoca la necesidad de enseñar lo "natural", la inclinación por lo opuesto, por el otro. Es interesante que, al discutir sobre el "invertido congénito", se mencionen cuestiones como el aspecto femenino o varonil, es 
decir, se habla de expresión de género, aunque, finalmente, esta observación queda absorbida por el tema sexual.

Para poder llevar a cabo dicha labor, se enfatiza en la necesidad de que todas las personas involucradas en la crianza de los niños tengan conocimiento sobre las diferentes etapas del desarrollo sexual para llegar al objetivo final, el cual, según la tesis de Guevara, consiste en que "de la escuela es de donde deben salir el hombre y la mujer plenamente dotados, tal como lo exige nuestra sociedad hoy día" (Guevara, 1941, p. 79). ¿Dotados de qué? Posiblemente de un instinto sexual "normal”.

En síntesis, se puede afirmar que la tesis de esta autora permite ver de manera amplia, algunas de las principales concepciones que existían con respecto a la educación sexual en Costa Rica, principalmente en la educación primaria. A inicios de la década de 1940, los argumentos y conceptos utilizados evidencian el grado de influencia que tenían las ideas sexológicas y psicoanalíticas más importantes del momento.

En repetidas ocasiones, el discurso de Guevara brinda ciertos elementos del proceso de construcción y regulación de la heterosexualidad. Esta es concebida como un instinto "natural" que debe ser constantemente guiado, canalizado y vigilado y, en ese sentido, la educación se convierte en una de las principales herramientas que permiten construir la normalidad sexual. Esta gran paradoja de tener que enseñar algo que, en teoría, es asumido como "natural e instintivo", es una contradicción que acompaña a la mayoría de los discursos sobre la heterosexualidad a lo largo del siglo XX. El hecho de que dicha paradoja se prolongue en el tiempo y esté presente en múltiples espacios institucionales y discursivos, da cuenta de que la construcción de la normalidad sexual se caracteriza por su precariedad, su fragilidad y por la facilidad con la que puede ser perturbada.

Esta tesis no fue publicada en forma de libro, por lo que su alcance y difusión, posiblemente, fue muy reducido. No obstante, se analizó en profundidad ya que expone algunas de las principales concepciones sobre la normalidad sexual presentes en el ámbito educativo costarricense de esos años que, como se vio anteriormente, también aparece de manera fragmentaria en las memorias institucionales.

\section{LA NORMALIDAD SEXUAL Y LA CULTURA POPULAR}

Anivel global, hubo varios modelos de educación sexual, sin embargo, después de la Segunda Guerra Mundial (1939-1945), empezó a consolidarse una educación orientada hacia la vida en familia, con roles de género determinados y formas apropiadas de criar a los hijos (Zimmerman, 2015). Asimismo, en el caso costarricense, los fondos que tenían por objetivo financiar a la educación pública aumentaron sostenidamente entre 1950 y 1960 (Molina, 2016, p. 352). Para la década de 1950, todavía no se había establecido, concretamente, un plan nacional de educación sexual, a pesar de los esfuerzos que se habían llevado a cabo desde décadas pasadas. El tema seguía siendo una gran laguna en la agenda de la enseñanza pública en Costa Rica. 
Sin embargo, la sexualidad y, especialmente, todo lo relacionado con la natalidad y el ciclo de la vida, era un tema presente en la discusión pública. La cuestión sobre qué hacer cuando un niño pregunta acerca del origen de las personas era algo que generaba angustia y recelo (“¿Debe el niño saber cómo nacemos?”, 1951, p. 9). En ese sentido, durante la década de 1950 se proyectaron películas que, al igual que los manuales de puericultura, ${ }^{9}$ trataban de dar una visión científica e informada acerca de los detalles de la formación de la vida.

Una de esas películas fue El origen de la natalidad,$^{10}$ una producción audiovisual que solo era permitida verla en compañía de adultos. Las funciones se proyectaban en función del género de los asistentes, en el Teatro Raventós para los hombres y en el Teatro América para las mujeres. La película se anunciaba como una experiencia emotiva y sentimental, en donde era posible observar por primera vez en la pantalla grande, el nacimiento de tres bebés a través de una operación de cesárea ("El origen de la natalidad," 1950a, p. 10). Al mismo tiempo, se instaba a las mujeres a asistir, especialmente se apelaba a las madres, con un eslogan que afirmaba "su hija está en peligro, USTED tiene la culpa porque faltó al deber como madre... nadie debe quedarse sin verla" ("El origen de la natalidad," 1950b, p. 14). De alguna manera, los temas de la película se perfilaban como un asunto de conocimiento obligatorio, la maternidad científica fue de los principales elementos que caracterizó a las dinámicas de género durante periodo de guerra fría, especialmente en Costa Rica (González, 2005, pp. 113-121).

La normalidad sexual y su relación con el tema de la procreación y la crianza de los hijos no era algo que se podía dejar simplemente en manos de la naturaleza, había que intervenir sistemáticamente, crear manuales y guías para que dicha procreación se diera bajo un control estricto de la ciencia y la higiene. La regulación de la heterosexualidad se vuelve crítica en los momentos donde se detecta gran inestabilidad o la presencia de grandes amenazas (Adams, 2012). Paradójicamente, frente a estos esfuerzos cinematográficos por educar a la población, una de las supuestas amenazas que se asomaba entre las grietas de la sociedad costarricense era, precisamente, el cine.

En columnas de periódicos se argumentaba que los jóvenes eran propensos a ser fácilmente influenciados, se decía que la mala educación era algo común y que había una evidente decadencia en las costumbres, una moral en declive, un desinterés y desgano. Se hacía un llamado para que los diferentes sectores de la sociedad actuaran los más pronto posible. En un artículo publicado en La Nación en 1952 se afirmaba que

No es posible que las autoridades conductoras de la educación pública vean con indiferencia este relajamiento que existe en la cultura de un pueblo que el maestro ha forjado en las aulas de la escuela y el colegio. Mucho se ha hablado ya acerca de las deficiencias de la enseñanza nacional. Nuestros muchachos, se dice, están saliendo de la escuela y de los colegios mal preparados (...) Los frutos que se palpan en la calle, en el hogar, en el salón, en todas las clases que forman la sociedad, no son, por cierto, los más apetecibles. Por doquiera se 
levanta una queja contra la decadencia moral en que nos estamos precipitando (...) La escuela, el hogar y la autoridad oficial deben recuperar su puesto de severos conductores y vigilantes de las costumbres sociales y enderezar los extravíos que estamos padeciendo y de que ya empezamos a lamentarnos con toda razón. ("El hogar y la escuela deben volver en sí," 1952, p. 2)

¿A qué se debía la percepción negativa de dicho panorama? En un contexto de posguerra, de tensiones políticas y de crecimiento demográfico, la percepción de que los viejos moldes sociales se reconfiguraban era palpable. La familia nuclear empezó a ser visualizada como la primera línea de defensa frente a los cambios que se desarrollaban día con día. Esta noción de degradación moral y cultural estaba también vinculada con la idea de que los robos y los crímenes eran crecientemente cometidos por personas jóvenes ("Aspectos sobre el problema moral y cultural de Costa Rica," 1952). Como muestra la anterior cita, se apelaba a la educación y al hogar como una manera de contener, vigilar y disciplinar a esos jóvenes que habían perdido el camino, que se habían extraviado.

En una carta publicada en prensa, dirigida al Dr. Carlos Caamaño, quien era el jefe inspector de Colegios de Segunda Enseñanza en Costa Rica, se le comunicaba que la incultura era el estado actual de la juventud. Se constataba que, dicho sector de la población estaba "rompiendo la honrosísima tradición costarricense" (Pío, 1952, p. 10). Y, aunque nunca se explica en qué consistía dicha tradición, se hizo una lista de las causas para esa incultura, entre ellas se citó al cine moderno, principalmente las cintas provenientes de México; la música vulgar, chabacana; la libertad de prensa que se dedica, principalmente, a publicar "las vergüenzas de las pasiones humanas"; las revistas gráficas donde abunda el "desnudo y las actitudes atrevidas, inmorales"; la novelas de bajo fondo moral, las cuales son de fácil acceso por cualquier persona; los anuncios comerciales; la desintegración familiar caracterizada por "uniones libres, divorcios, adulterios públicos, amores libres, borracheras, lenguaje libertino, poca o ninguna instrucción moral," y la falta de autoridad moral por parte de los profesores (Pío, 1952, p. 10).

En cierta forma, la juventud era representada como un actor social que se encontraba en un estado permanente de naufragio, perdido y con necesidad de ser guiado por el camino adecuado. Pero dicho camino se encontraba lleno de obstáculos, en la forma de una "incultura", que tenía el potencial de romper las más básicas tradiciones que caracterizaban a la imagen idealizada del país que tenían ciertos sectores de la población. El cine fue repetidamente mencionado como uno de esos elementos que obstaculizaba la buena formación de los jóvenes, incluso se llegó a formar una Oficina de Censura Católica Cinematográfica, la cual, para 1950, llevaba a cabo una serie de conferencias sobre la higiene cinematográfica y los mecanismos que utilizaban para clasificar las películas; su principal objetivo era proscribir los "malos espectáculos" y alentar aquellos que "no rebajen las normas de moralidad del espectador" ("Defensa nacional de principios cristianos," 1950, p. 15). 
El discurso sobre la necesidad de depurar el contenido de las salas de cine llegó hasta las aulas. Por ejemplo, el 23 de abril de 1950, unas 400 alumnas del Colegio de Sión se manifestaban a través de una carta, debido a su inconformidad con el hecho de que se exhibieran películas "escabrosas y condenadas”, así como de carácter "amoral e irrespetuoso". Su protesta iba dirigida a los empresarios encargados de traer dicho material audiovisual, alentándolos a recapacitar sobre el potencial corruptor de sus escogencias, y se reafirmaba la capacidad instructiva del "buen cine" en la formación de la juventud ("Cuatrocientas alumnas del Colegio de Sión hacen un ruego a los empresarios de Teatros," 1950, p. 7).

De igual manera, se hacía un llamado para que los cines alrededor de la ciudad de San José no permitieran el ingreso de menores en sus funciones ("Sanción a los empresarios que permitan la entrada de menores," 1952). Como se puede observar, las supuestas amenazas eran múltiples y venían de distintas direcciones, la juventud se encontraba desprotegida, y circulaba la noción de que la legislación nacional no era lo suficientemente contundente ("Instancia para reforma al Código Penal," 1955) para protegerla en ámbitos como el de la sexualidad.

Uno de los principales mediadores en la producción de "conocimiento experto" sobre el tema de la niñez, la juventud y la sexualidad en este contexto fue Luis Felipe González Flores, quien, además de haberse desempeñado como docente, fue parte de la subsecretaría de Instrucción Pública en 1914. González Flores fue el fundador del Departamento Sanitario Escolar y presidente del Patronato Nacional de la Infancia, además de sus labores en distintas instituciones, también tuvo publicaciones variadas, entre las cuales resaltan reglamentos (González, 1995). En 1950 publicó un artículo en donde abordaba el tema de la prostitución en menores de edad. En dicho texto, se explaya ampliamente sobre el tema de la homosexualidad, al caracterizarla como

\footnotetext{
Una fundamental anomalía de la vida sexual, ha sido estudiada por muchos médicos y psicólogos contemporáneos y es conocida corrientemente con el nombre de inversión sexual. Junto con los vicios sexuales solitarios, el problema de la homosexualidad debe ser objeto de una delicada y permanente observación de parte de los padres y maestros de los menores para evitar en esto malas consecuencias que ambos tienen en su salud física y moral. El problema tiene su origen en perturbaciones endocrinas que producen estados intersexuales, en el ambiente de prejuicios estrechos y anticuados y en la libertad de que hacen uso y en que crecen los menores, como una reacción o desquite de la renunciación obligada de las excesivas y atormentadas limitaciones impuestas (...)en la pubertad propiamente dicha, se presentan las prácticas de inversión sexual y los vicios sexuales solitarios en los menores, y es en aquélla época cuando la observación de las manifestaciones morales y patológicas debe redoblarse de parte de los padres y de los educadores. (González, 1950, p. 9).
}

Nuevamente, las tres principales amenazas a la normalidad sexual aparecen en el discurso. La masturbación, la homosexualidad y la intersexualidad (anteriormente llamada hermafroditismo), se erigen como esas milicias que asechan la fortaleza creada para proteger a la familia nuclear, a las personas jóvenes y al propio "instinto sexual 
natural". Conforme dichas amenazas se acercan, su presencia provoca que las defensas se vean reforzadas. La familia nuclear, las tradiciones y la juventud conforman una triada opuesta - como en negativo - la cual es abordada en los discursos, se evidencia su vulnerabilidad y, por lo tanto, se crean las justificaciones necesarias para protegerla.

Dentro del discurso de González, en ningún momento se menciona la heterosexualidad. El reflejo opuesto de la supuesta patología que está describiendo se encuentra sobre la superficie, pero nunca es nombrada, su presencia es naturalizada y tomada por sentado. Dicha afirmación es posible ya que esta caracterización de la homosexualidad, tan temprana en el contexto costarricense, presupone que el autor muy posiblemente estaba al tanto de algunos de los más importantes tratados sexológicos del momento. La descripción de esta "anomalía" como una amenaza que, junto a la masturbación y la intersexualidad, pueden tener consecuencias negativas en los jóvenes, evidencia que el proceso de construcción de la "normalidad" sexual era algo delicado, algo a lo que había que ponerle atención, de lo contrario, fácilmente se podía desviar el camino. Y, en ese sentido, una vez más, son los docentes y los padres de familia los llamados a convertirse en guardianes de la moralidad, en vigilantes de los comportamientos, supervisores de las actitudes sexuales de sus hijos y estudiantes.

Otros aspectos que llaman la atención sobre las declaraciones de González son las diferentes menciones que se establecen acerca del origen de la "inversión sexual”. Por un lado, hace énfasis en la causación biológica, anclada en los trastornos endocrinos ${ }^{11} \mathrm{y}$, por otro lado, menciona algunos factores sociales como el grado de libertad, la necesidad de rebeldía y la imposición de valores y prejuicios obsoletos. ¿Cuál tenía más peso? ¿Es acaso esta una forma de conceptualizar la homosexualidad donde tanto lo biológico como lo social tenían un peso equitativo? Y, en ese caso, para que la persona lograra convertirse exitosamente en un "adulto normal" ¿también se veía influenciado por ambos mundos, el natural y el social? Se podrían hacer muchas conjeturas alrededor de esta intervención periodística, lo importante de recalcar es que ya desde antes de la década de 1950, el opuesto de la "normalidad" sexual; la "inversión" y la "anomalía", conformado a partir de una triada, tenían un lugar simbólico como amenazas latentes, al menos en el corpus de textos analizados.

En la intervención de González es posible notar una ambivalencia en cuanto al origen de la homosexualidad que describe en su texto. Al mismo tiempo, permite evidenciar, hasta cierto punto, el grado de alcance que tenían las teorías sobre la sexualidad en el ámbito nacional. Estas discusiones presentes en los medios de comunicación escrita son importantes, ya que muestran la forma en que las nociones sobre la normalidad sexual que habían adquirido forma desde la intelectualidad higienista, médica y educativa empezaban a tener una mayor presencia en la cultura popular. Las preocupaciones sobre las actitudes de la juventud, los roles de género, la maternidad, el acceso al cine y la música moderna, la pornografía, las novelas eróticas y la publicidad son elementos que evidencian una creciente cultura de masas a mediados del siglo XX, cultura que estaba permeada - hasta cierto punto - por los debates e ideas sobre la normalidad sexual que se habían desarrollado desde años anteriores. 


\section{CONCLUSIÓN}

Convertirse en una persona normal durante la primera mitad del siglo XX no era algo fácil, requería de atención, trabajo, esfuerzo y constante vigilancia, y no había garantía de éxito (Cryle y Stephens, 2017). Tanto la sexología, como el higienismo, la educación sexual, la salud pública, la eugenesia y el psicoanálisis tuvieron un papel fundamental en establecer el rol de la sexualidad como eje central en la conformación de la normalidad. Los discursos analizados permiten evidenciar que, para la época, en Costa Rica había un verdadero intercambio de saberes, provenientes en su mayoría de algunas regiones de Europa.

A través de las distintas publicaciones y discusiones públicas, estos lugares de enunciación discursiva permitieron que la figura de la persona normal ocupara, paulatinamente, un espacio en el imaginario popular. Como dos caras de una misma moneda, el proceso de construcción y regulación de la heterosexualidad estuvo acompañado del establecimiento de amenazas y, por lo tanto, se legitimaba cualquier tipo de acción con tal de defenderla. Analizar este ir y venir entre la "normalidad" y la "anormalidad" sexual es necesario para comprender el tipo de discusiones y políticas - de sexualidad y género - que se implementarán en Costa Rica a lo largo de la segunda mitad del siglo XX.

La construcción de la normalidad sexual desde los discursos higienistas, científicos y sexológicos dan cuenta de que, para las décadas de 1930 y 1940, había una necesidad por parte de dicha intelectualidad de llevar estos saberes al grueso de la población mediante la publicación de manuales y folletos. Dichos discursos analizados parten de la idea de la heterosexualidad como un "problema" que debía ser atendido.

Junto a estos discursos, el sistema educativo también tuvo un papel fundamental en la propagación de información sobre la sexualidad. Las menciones fragmentarias que se pueden encontrar en las memorias institucionales evidencian que no era un asunto completamente ajeno a los contenidos abordados en las aulas. En la tesis examinada es posible observar de forma más amplia algunas de las nociones que había en el país en torno a la educación sexual, la normalidad y las posibles amenazas que podían desviar del camino correcto a los estudiantes. Eventualmente, estos saberes y discursos empezaron a tener una mayor presencia en la cultura popular, mediante la discusión mediática de ciertas problemáticas que evidenciaban, una vez más, el papel central de la normalidad sexual en la regulación de los comportamientos y en la propia conformación de subjetividades.

Como mencionan Cryle y Stephens (2017) en su análisis genealógico de la normalidad, uno de los principales supuestos que se han desarrollado con este tema, ha sido la idea de que lo normal tiene una lógica coherente y que, por lo tanto, exponer sus incoherencias y contradicciones permitiría socavar su hegemonía y funcionalidad (p. 9). Este análisis, para el caso costarricense, evidenció que ese carácter precario, paradójico e inestable ha estado presente en los discursos sobre la normalidad sexual durante el periodo analizado. Lo normal es heterogéneo, es variable, se adapta al contexto, su 
incoherencia conceptual es - en parte - lo que le permite adquirir su fuerza y autoridad cultural. Un entendimiento amplio y crítico sobre la manera en que se ha construido a lo largo del tiempo permite tomar consciencia de esas dinámicas. El gran poder simbólico que posee la normalidad tiene efectos materiales en la vida de muchas personas, por lo que no se le puede tomar por sentado.

\section{NOTAS}

1 Con relación a la circulación transatlántica de saberes, es importante tomar en cuenta que Europa durante la primera mitad del siglo XX pasaba por profundas transformaciones geopolíticas. En ese sentido, los saberes que circulaban eran sometidos a diversas adaptaciones y modificaciones, por lo que se trataba de elementos inestables que podían ser reapropiados en otros contextos, como el costarricense. Es necesario tener presente tanto el contexto de formación de saberes, así como el contexto de recepción e interpretación. Vetö (2014) ha investigado esta cuestión de forma más amplia para el caso chileno durante el mismo periodo.

2 Dennis Arias (2016) hace un análisis bastante detallado del desarrollo del higienismo en Costa Rica (pp. 46-66).

3 Aunque la Iglesia tiene un papel sumamente importante en los procesos de construcción de la normalidad sexual, en este artículo no se abordarán los discursos religiosos, ya que el énfasis está sobre lo médico-científico, lo educativo y lo mediático. Para un análisis de las posiciones, discursos y prácticas provenientes de la Iglesia se puede revisar a Quesada (2012) y Flórez (2017).

Richard von Krafft-Ebing, uno de los sexólogos más importantes del siglo XIX, establecía que la función sexual normal implicaba más que la capacidad física para tener relaciones sexuales, al abarcar toda una serie de estados psicológicos y procesos dinámicos. La normalidad y la anormalidad sexual no eran, desde esta perspectiva, conceptos opuestos y antagónicos, al contrario; se traslapaban y, por lo tanto, el deseo sexual podía manifestarse anormalmente de varias maneras, podía darse en el momento erróneo (paradoxia), en una cantidad inadecuada (anestesia e hiperestesia), o hacia un objeto equivocado (parestesia) (Cryle y Stephens, 2017, p. 269).

5 En dicho texto, Freud comienza diciendo que "forma parte de la opinión popular acerca de la pulsión sexual la afirmación de que ella falta en la infancia y sólo despierta en el periodo de la vida llamado pubertad. No es este un error cualquiera: tiene graves consecuencias, pues es el principal culpable de nuestra presente ignorancia acerca de las bases de la vida sexual...Parece seguro que el neonato trae consigo gérmenes de nociones sexuales que siguen desarrollándose durante cierto lapso, pero después sufren una progresiva sofocación...Parece, empero, que casi siempre hacia el tercero o cuarto año de vida del niño, su sexualidad se expresa en una forma asequible a la observación (Freud, 1992a, pp. 157-160).

6 Queda como tema pendiente por investigar, la influencia del pensamiento freudiano en el ámbito educativo costarricense en la larga duración.

7 Thomas Laqueur (2007) menciona que "No siendo ya una amenaza para la salud, el sexo con uno mismo podía representar un rechazo no sólo de una sexualidad socialmente apropiada, no sólo de una sociabilidad adecuada, sino también del propio orden social. La masturbación, que durante mucho tiempo había sido construida como el mayor de los desafíos a la política moral, 
se volvió una amenaza aún más catastrófica y atávica. Al no colmar más los hospitales mentales ni figurar en las estadísticas de mortalidad, quedaba finalmente libre de sus epifenómenos y podía revelarse en toda su desnudez como lo que siempre se había sospechado que era: el colapso de la cultura y el retorno al nivel más primitivo de deseo y gratificación (...) La culpa y sus costos psíquicos reemplazaron la muerte y la locura, pero no eran menos aterradores e importantes por ser menos orgánicamente mórbidos... La masturbación siguió siendo crucial para el pensamiento sobre la sexualidad y el yo, pero en un nuevo registro, un aterrador nuevo registro en que el antiguo objetivo del sexo y sus placeres - la reproducción - ya no podía darse por supuesto" (pp. $421-423$ ).

Un fenómeno similar en cuanto al uso de múltiples significantes se puede encontrar en el análisis que hace Patricia Alvarenga de los juicios por sodomía en Costa Rica a inicios del siglo XX (Alvarenga, 2012, pp. 286-293).

En 1949 aparece el primer Boletín de Puericultura, el cual era editado por el Ministerio de Salubridad Pública y que aparecía de forma irregular los domingos en algunos de los principales periódicos nacionales, en dichos boletines se buscaba construir y fomentar una salud maternoinfantil estrictamente bajo la perspectiva médico-científica moderna (González, 2005, p. 113).

10 Originalmente, publicada en 1945 con el título "Mom and Dad" y producida por Hygienic Productions. La película dura alrededor de una hora y treinta minutos, y trata sobre una adolescente que en su primera experiencia sexual queda embarazada, al acudir a su madre por consejo, es rechazada. La joven entonces se acerca a un profesor que había sido despedido por impartir educación sexual, y este le provee de información básica sobre la maternidad. La película fue una de las más exitosas en su estilo y fue ampliamente distribuida a diferentes partes del mundo, aunque también sufrió la censura y la prohibición en ciertas regiones (Black, 1999, p. 432).

11 En el tránsito del siglo XIX al XX, los avances en temas relacionados con la endocrinología empezaron a dar luces acerca de la cuestión del comportamiento sexual humano, permitiendo que el modelo hormonal empezara a consolidarse. En ese contexto, es posible que la perspectiva de González esté directamente influenciada por algunos de los sexólogos más importantes de la primera mitad del siglo XX; entre ellos el británico Havelock Ellis juega un papel fundamental. Autor del libro Sexual Inversion, publicado en 1897, fue durante mucho tiempo la única contribución sistemática sobre la clasificación teórica de la homosexualidad. Ellis argumentaba que cuando la inversión era inherente, es decir una "homosexualidad innata", esta tenía que ser descrita como una anomalía biológica, determinada por irregularidades hormonales (Weeks, 2012, pp. 190-194).

\section{REFERENCIAS}

Adams, M. (2012). The Trouble with Normal. Toronto: University of Toronto Press.

Allouch, J. (2003). “Horizontalidades del sexo.” Revista Página Literal, (1), pp. 33-52.

Alvarenga, P. (2012) Identidades en disputa. Las reinvenciones del género y la sexualidad en al Costa Rica de la primera mitad del siglo XX. Costa Rica: Editorial UCR.

Amador, J. (1946, 22 de abril) Síntesis de la lucha antivenérea en Costa Rica [ponencia]. Primer Congreso Centroamericano de Venereología. Panamá. 
Arias, D. (2016). Héroes melancólicos y la odisea del espacio monstruoso. Metáforas, saberes y cuerpos del biopoder (Costa Rica, 1900-1946). San José: Editorial Arlekín.

Aspectos sobre el problema moral y cultural de Costa Rica. (1952, 5 de febrero). La Nación, p. 4.

Black, G. (1999). La cruzada contra el cine (1940-1975). Madrid: Cambridge University Press.

Costa Rica (1928). Memoria de la Secretaría de Educación Pública. San José: Imprenta Nacional.

Costa Rica (1929). Memoria de la Secretaría de Educación Pública. San José: Imprenta Nacional.

Costa Rica (1936). Memoria de la Secretaría de Educación Pública. San José: Imprenta Nacional.

Costa Rica (1937). Memoria de la Secretaría de Educación Pública. San José: Imprenta Nacional.

Costa Rica (1939). Memoria de la Secretaría de Educación Pública. San José: Imprenta Nacional.

Cryle, P. y Stephens, E. (2017). Normality. A Critical Genealogy: Chicago: Chicago University Press.

Cuatrocientas alumnas del Colegio de Sión hacen un ruego a los empresarios de Teatros. (1950, 23 de abril). La Nación, p. 7.

¿Debe el niño saber cómo nacemos? (1951, 5 de diciembre). La Nación, p. 9.

Defensa nacional de principios cristianos. (1950, 15 de abril). La Nación, p. 15.

Díaz, D. (2010). Reforma sin alianza, discursos transformados, interés electoral, triunfos dudosos. San José: Editorial UCR.

El hogar y la escuela deben volver en sí. (1952, 10 de enero). La Nación, p. 2.

El origen de la natalidad. (1950a, 18 de enero). La Nación, p. 10.

El origen de la natalidad. (1950b, 19 de enero). La Nación, p. 14.

Flores, M. (2007). La construcción cultural de la locura femenina en Costa Rica (1890-1910). Costa Rica: Editorial UCR.

Flórez-Estrada, M. (2017). Discursos sobre la maternidad moderna y la reforma social costarricense (décadas 1930-1940). [Tesis de doctorado en Estudios de la Sociedad y la Cultura, Universidad de Costa Rica] Repositorio.

Foucault, M. (1999). El orden del discurso. Barcelona: Tusquets.

Freud, S. (1992a). Obras Completas. Tomo VII. Buenos Aires: Amorrortu Editores.

Freud, S. (1992b). Obras completas. Tomo XIV. Buenos Aires: Amorrortu Editores. 
Gamboa, I. (2009). En el Hospital Psiquiátrico: El sexo como (lo)cura. Costa Rica: Grafos Litografía.

González, L. (1995). Reglamentación de espectáculos para menores no limitado a cines y teatros, sino a la radio y la televisión cuyos programas se reproducen en el mismo lugar. San José: Imprenta Nacional.

González, L. (1950, 8 de agosto). La prostitución de menores como factor de delincuencia. La Nación, p. 9.

González, A. (2005). Mujeres y hombres de la posguerra costarricense (1950-1960). San José: Editorial de la Universidad de Costa Rica.

Guasch, O. (2000). La crisis de la heterosexualidad. Barcelona: Laertes.

Guevara, J.(1941).El problema sexual en la escuela. [Tesis de grado en enseñanza primaria, Universidad de Costa Rica]. Repositorio.

Instancia para reforma al Código Penal. (1955, 3 de febrero). La Nación, p. 2.

Katz, J. (2012). La invención de la heterosexualidad. México: Editorial Me cayó el veinte.

Laqueur, T. (2007). Sexo solitario: Una historia cultural de la masturbación. Buenos Aires: Fondo de Cultura Económica.

Láscaris, C. (s.f.) "Bibliografía Pablo Luros.” Revista de Filosofía, 3(11), pp. 355-358.

Luros, P. (1939). Salud y matrimonio. San José: Imprenta Borrase.

Luros, P. (1941). El sentido de la vida (según la psicología individual). San José: Imprenta Borrase.

Marín, J. (2000). "De curanderos a médicos. Una aproximación a la historia social de la medicina en Costa Rica: 1800-1949.” Diálogos Revista Electrónica de Historia, 1(2), pp. 65-108.

Marín, J. (2002). Biblias de la higiene. Las cartillas terapéuticas en Costa Rica (1864-1949). En Francisco E. Solano e I. Molina (Compiladores). Culturas populares y políticas públicas en México y Centroamérica (siglos XIX y XX). (pp. 1-46). Alajuela: Museo Histórico Cultural Juan Santamaría.

Molina, I. (2016). La educación en Costa Rica de la época colonial al presente. San José: EDUPUC.

Molina, I. (2019). "Deliciosas tempestades: las mujeres y la educación sexual en Costa Rica entre las décadas de 1920 y 1960.” Descentrada, 3(1), doi: https://doi.org/10.24215/25457284e066

Palmer, S. (1996). "Racismo intelectual en Costa Rica y Guatemala, 1870-1920.” Mesoamérica, (31), pp. 99-121.

Pío, A. (1952, 8 de febrero). El cine, la música, la libertad de prensa, las revistas gráficas, los anuncios, el hogar y el profesorado, son las causas más frecuentes de esta nueva corriente de incultura en nuestra juventud. La Nación, p. 10. 
Pupo, C. (1936). Nuestros males. Principios sanitarios que nadie debe ignorar. San José: Imprenta y Fotografía Alsina.

Quesada, C. (2012). "Familia y heteronormatividad: acontecimientos históricos y la doctrina sexual de la Iglesia Católica en Costa Rica.” Anuario de Estudios Centroamericanos, (38), pp. 305-328

Rodríguez, E. (2008). Dotar de voto político a la mujer. San José: Editorial UCR.

Sanción a los empresarios que permitan la entrada de menores. (1952, 4 de marzo). La Nación, p. 19.

Tin, L. (2012). La invención de la cultura heterosexual. Buenos Aires: El Cuenco de Plata

Vetö, S. (2014). "Psicoanálisis, higienismo y eugenesia: educación sexual en Chile, 1930-1940". Nuevo Mundo Nuevos Mundos (2014) https://doi.org/10.4000/nuevomundo.66920

Weeks, J. (2012). Sex, Politics, and Society: the regulation of sexuality since 1800. United Kingdom: Pearson Education Limited.

Zimmerman, J. (2015). Too hot to handle: a global history of sex education. New Jersey: Princeton University Press. 